\title{
PRIMEIRO, O BÁSICO. DEPOIS, O RESTO: O DIREITO À RENDA BÁSICA
}

\section{FIRST, THE BASIC. THEN, THE REST: THE RIGHT TO BASIC INCOME}

\section{ZELIA LUIZA PIERDONÁ}

Pós-doutora pela Universidade Complutense de Madri. Doutora e Mestre em direito pela PUC-SP. Professora do Programa de Pós-Graduação stricto sensu da Universidade Presbiteriana Mackenzie. Procuradora Regional da República.

\section{ANDRE STUDART LEITÃO}

Doutor e Mestre em Direito pela PUC-SP. Pós-doutorando em Direito pela Universidade Presbiteriana Mackenzie. Pós-doutorando em Direito pela UNIFOR.

\section{EMMANUEL TEÓFILO FURTADO FILHO}

Doutor em Direito pela Universidade de Paris V. Mestre em Direito pela Universidade de Le Havre. Graduado em Direito pela UFC. Advogado. Professor universitário.

\section{RESUMO}

Um dos objetivos da República Federativa do Brasil é a erradicação da pobreza e a redução dos desníveis socioeconômicos. Segundo a atual conjuntura pátria, o compromisso constitucional, ao mesmo tempo em que configura uma pauta social inescapável, pode ser considerado um desafio de difícil realização. Existe um grave problema de genética social, cuja superação depende da desparametrização da igualdade, da desconstrução do individualismo jurídico, do fortalecimento da solidariedade e da veiculação harmoniosa de diversas políticas públicas de focalização específica. Este ensaio não pretende fornecer uma solução definitiva para a pobreza e as desigualdades sociais. Pretende-se, ao invés, partindo da 
premissa de que a escassez envolve, a um só tempo, a carência de recursos e uma psicologia típica, defender que a providência preliminar da extensa pauta social deveria ser a transferência de uma renda básica que atendesse ao critério da suficiência.

PALAVRAS-CHAVE: Igualdade; Coletividade; Escassez; Assistência Social E Renda Básica.

\begin{abstract}
One of the objectives of the Federative Republic of Brazil is the eradication of poverty and the reduction of socioeconomic disparities. According to the current national context, the constitutional commitment, at the same time as it constitutes an inescapable social agenda, can be considered a difficult challenge. There is a serious problem of social genetics, whose overcoming depends on the deparametrisation of equality, the deconstruction of legal individualism, the strengthening of solidarity and the harmonious placement of several public policies of specific focus. This essay is not intended to provide a definitive solution to poverty and social inequalities. Instead, it is intended to assume that scarcity involves both a lack of resources and a typical psychology, to argue that the primary providence of the broad social agenda should be the transfer of a basic income that sufficiency criterion.
\end{abstract}

KEYWORDS: Equality; Collectivity; Scarcity; Social Assistance And Basic Income.

\title{
INTRODUÇÃO
}

No conforto de seu automóvel blindado, ao som de uma banda irlandesa, enquanto um cidadão esperava pacientemente pelo sinal verde em um cruzamento movimentado da cidade, três imagens Ihes chamaram atenção. A primeira era representada por um grupo de crianças pobres que se esforçavam com desastrados 
gestos malabaristas. A segunda foi um senhor de aproximadamente sessenta anos que só chamou a atenção do motorista depois de tocar suavemente seu vidro em busca de alguns trocados. A aparição repentina aconteceu porque aquele homem não caminhava com as pernas. Ele rastejava com os braços esguios, mas de musculatura bastante definida, certamente em virtude de seus esforços de movimentação. A última imagem era um indivíduo aparentemente saudável com cerca de trinta anos. Seu rosto sobejava, a um só tempo, tristeza e desesperança. Vestia trapos e segurava uma placa com a informação "estou com fome".

Sensibilizado, o cidadão viu-se diante de um dilema: qual deles deveria ajudar? As crianças, o homem com deficiência ou o maltrapilho? Em poucos segundos, ponderou diversos fatores e concluiu: "Aquelas crianças deveriam estar na escola. Aquele maltrapilho é jovem e pode trabalhar. Mas o que dizer do senhor que rastejava? Definitivamente, ele é o mais vulnerável."

Convicto da justiça de seu julgamento, cautelosamente, o motorista baixou alguns centímetros do vidro e arremessou duas moedas. Elas tocaram o chão. Satisfeito, o escolhido rastejou em direção ao prêmio. Não houve comunicação entre os envolvidos. Enquanto isso, de dentro do carro, o motorista esboçou um sorriso confortante. Em sua opinião, naquele dia, tinha feito a diferença na vida de um infeliz.

De certa maneira, a narrativa é uma ficção baseada em uma história real brasileira. Aliás, uma ficção baseada em milhões de histórias reais brasileiras. Nas grandes metrópoles, mendigos duelam em semáforos, em praças públicas ou em calçadões em busca de trocados. Ora são malabaristas, ora, palhaços, ora, esportistas, ora, gestantes, ora, crianças, ora são simplesmente miseráveis. Todos têm uma característica comum: são subcidadãos (Souza, 2015, p. 69-89).

No Brasil, a mendicância integra a cinzenta paisagem urbana, proporcionando ganhos simbióticos para os envolvidos ou, pelo menos, para aqueles que escolhem se envolver. Enquanto miseráveis lucram algumas dezenas de reais, doadores repousam aliviados com a aprazível sensação de que ajudaram o próximo e que, por isso, serão recompensados com um camarote no reino dos céus.

Há três pontos de partida fundamentais: $\left.1^{\circ}\right)$ no Brasil, a marginalização, independentemente do fator de origem, é um dado social irrefutável; $2^{\circ}$ ) alguma 
coisa, ou a falta de alguma coisa, está impedindo que o compromisso constitucional seja realizado; $3^{\circ}$ ) a fórmula para solução de todas as mazelas sociais não pressupõe a falaciosa (e porque não dizer distópica) ideia de igualdade.

Por que o Brasil está tão longe de construir uma sociedade livre, justa e solidária, de erradicar a pobreza e a marginalização e reduzir as desigualdades sociais e regionais e de promover o bem de todos sem preconceitos $\mathrm{e}$ discriminações?

Existem dezenas de respostas para essa pergunta. O objetivo deste ensaio não é apresentar uma solução definitiva para a pobreza e os gravíssimos desníveis socioeconômicos brasileiros, mas indicar o primeiro passo de uma longa caminhada.

Evidentemente, a indicação do primeiro passo depende de uma rede conexa de argumentos. Preliminarmente, serão discutidas questões estruturantes da problemática social: igualdade, diferença, parametrização, coletividade e individualismo. O capítulo intermédio confere consistência argumentativa ao recorte epistemológico, pois define a escassez de recursos e seus efeitos materiais e psicológicos como os principais entraves para a realização do desenvolvimento. Em sequência, defende-se a garantia de uma "folga" (pecuniária) por meio da instituição de um programa de renda básica como mecanismo capital de combate à pobreza.

\section{IGUALDADE, DIFERENÇA E PARAMETRIZAÇÃO}

Ao discorrer sobre a crise do Estado-providência, Pierre Rosanvallon (1997, p. 29) erige um complexo questionamento essencial: a igualdade é um valor que ainda tem futuro? O historiador francês salienta que a igualdade pode ser analisada sob duas traduções diferentes: $1^{1}$ ) civil ou política, enquanto igualdade de todos perante a lei e sufrágio universal; $2^{2}$ ) econômica ou social.

Em relação à primeira perspectiva, parece não haver dúvida de que o valorigualdade pode ser considerado o principal mecanismo jurídico de combate à discriminação. De outro giro, a demanda por igualdade socioeconômica se exprime como vontade de redução das desigualdades. Existe unanimidade quanto ao discurso de redução das desigualdades sociais. Porém, ninguém reivindica a 
igualdade geradora de identidade. Em síntese: todos concordam em reduzir as desigualdades, mas ninguém aprova a implementação de medidas de acesso à igualdade absoluta. É justamente no cerne desse paradoxo em que se encontra o abalo intelectual do Estado-providência (Rosanvallon, 1997, p. 30).

Limitando-se a uma avaliação puramente econômica e quantitativa, existem duas maneiras de realizar a igualdade absoluta. A primeira possui viés redistributivo, pois retira de uns para entregar para outros com base em um cálculo aritmético simples. Imagine-se um grupo de três pessoas. Se uma delas $\left(A_{1}\right)$ possui uma riqueza quantificada em noventa unidades, e as demais ( $A_{2}$ e $A_{3}$ ), em trinta (cada uma), a igualdade econômica resultaria em um cálculo médio de riqueza de cinquenta unidades $(90+30+30=150 / 3=50)$. O Estado recolheria quarenta unidades do indivíduo mais abastado e redistribuiria para os demais ${ }^{1}$. A segunda maneira de efetivar a igualdade econômica decorre da intervenção predatória do Estado, que confiscaria a riqueza sem nenhuma contrapartida. Valendo-se do mesmo exemplo hipotético, o Estado confiscaria sessenta unidades de $A_{1}$, impondo o nivelamento econômico, pois a renda de todos passaria a ser de trinta unidades.

Enquanto o segundo modelo revela um cenário de absoluta distopia, o primeiro, apesar de teoricamente tangível, é inviável em termos práticos, afinal a experiência socialista fracassou e provavelmente não terá outra chance de impor a (falsa) ideologia dos iguais.

Para além de aspectos puramente jurídicos e sociológicos, existe outra valiosa perspectiva da igualdade: a que envolve aspectos biogenéticos, poderes e habilidades. Com efeito, simples diferenças genéticas, como boa saúde, QI elevado e estatura acima da média, são suficientes para diferenciar e atribuir vantagens decisivas no competitivo mundo contemporâneo. Um desenvolto jovem de 1,90 possui melhores chances de tornar-se um jogador profissional de basquete do que outro de 1,65, e o Estado nada pode fazer para equilibrar o potencial de ambos. Admitir o contrário equivaleria defender o mundo distópico de Harrison Bergeron (on line), onde impera a mais absoluta igualdade em todos os sentidos (ninguém mais

\footnotetext{
1 Num cenário ideal e sem perdas. Desconsidera-se a teoria do balde furado, segundo a qual não existe transferência gratuita de dinheiro de ricos para pobres, pois, inevitavelmente, parte do dinheiro desaparece em trânsito, de modo que os pobres não recebem todo o dinheiro que é retirado dos ricos.
} 
esperto do que ninguém; ninguém mais bonito do que ninguém; ninguém mais forte ou rápido do que ninguém).

O fato é que as pessoas nunca serão iguais. A própria ideia de igualdade de oportunidades não é tão genuinamente igualitária, porquanto a desigualdade de resultados da geração atual é uma fonte de vantagem injusta para a geração seguinte (Atkinson, 2015, p. 33-34). A quantificação das oportunidades pela riqueza facilita a compreensão deste argumento. Imaginem-se três indivíduos ( $B_{1}, B_{2}$ e $\left.B_{3}\right)$ que larguem exatamente do mesmo ponto de partida em questão de riqueza (10 unidades). Ao final da vida, $B_{1}$ acumulou uma fortuna de 100 unidades; $B_{2}$ triplicou seu patrimônio inicial; finalmente, B3 encerrou sua vida em situação de completa escassez. Vê-se que a igualdade de oportunidades de uma geração culminou com a desigualdade de resultados dessa mesma geração e, consequentemente, com a desigualdade de oportunidades da geração seguinte. Mesmo considerando a incidência do tributo de herança, os filhos de $B_{1}, B_{2}$ e $B_{3}$ partirão de posições diferentes. Os filhos de $\mathrm{B}_{1}$ terão à sua disposição melhores oportunidades do que os filhos de $B_{2}$ e de $B_{3}$.

\begin{tabular}{|c|c|c|c|c|}
\hline & $\begin{array}{c}\text { Ponto de partida } \\
\text { (riqueza) }\end{array}$ & $\begin{array}{c}\text { Final da vida } \\
\text { (riqueza) }\end{array}$ & & $\begin{array}{c}\text { Ponto de partida } \\
\text { (riqueza) }\end{array}$ \\
\hline $\mathrm{B}_{1}$ & 10 & 100 & Filho de $B_{1}$ & 100 \\
\hline $\mathrm{B}_{2}$ & 10 & 30 & Filho de B2 & 30 \\
\hline $\mathrm{B}_{3}$ & 10 & 0 & Filho de B3 & 0 \\
\hline
\end{tabular}

Se a diferença é uma condição inerente à humanidade, só existe uma alternativa: utilizá-la em benefício dos menos favorecidos. Esse, aliás, é o conteúdo de um dos princípios centrais da Teoria da Justiça de John Rawls (1997, p. 64): as desigualdades sociais e econômicas devem ser ordenadas de tal modo que sejam consideradas como vantajosas para todos dentro dos limites do razoável (princípio da diferença).

As diferenças são fundamentais para o desenvolvimento das coletividades. As diversidades culturais, étnicas, intelectuais etc. enriquecem o somatório de valores individuais, democratizam os ambientes e contribuem para o fortalecimento 
da tolerância entre os seres humanos e entre os povos. Sendo assim, o compromisso constitucional de reduzir as desigualdades parece extremamente atraente e justo. Consequentemente, a perspectiva social da igualdade não pode ser considerada um dos núcleos principiológicos do ordenamento jurídico.

Esse é um argumento importante para defender uma tese aparentemente paradoxal e contraditória: o objetivo das políticas públicas não deve ser diretamente a redução dos desníveis socioeconômicos. Sendo mais claro: de fato, a redução das desigualdades é um dos objetivos da República; porém, a realização desse objetivo depende de políticas públicas que não visem diretamente à redução das desigualdades. Ao invés disso, a melhor estratégia é implementar medidas de valorização da condição humana. A redução das desigualdades é uma consequência, um resultado.

A estratégia de focalizar em mecanismos de proteção da dignidade humana tem fundamento no enfoque das capacidades, idealizado por Amartya Sen (2000) e Martha Nussbaum (2013).

Para Amartya Sen (2000, p. 17), o desenvolvimento é um processo de expansão das liberdades reais que as pessoas desfrutam. Sua doutrina agrega o componente ético na economia, pois dissocia as noções de desenvolvimento (multidimensional) e crescimento econômico puro. Note-se que a concepção seniana independe de parametrização social. Não se trata, pois, de investigar se o indivíduo A é mais livre ou tão livre quanto o indivíduo B. Para o economista indiano, ambos devem ser livres.

A igualdade é um valor gregário, pois pressupõe parametrização. Não faz sentido reclamar identidade (igualdade) consigo mesmo. Pessoas reclamam o direito de serem iguais a outras que estão em melhor condição (nunca em pior). O problema é que a linha que separa o discurso igualitário do sectarismo é tênue, sobretudo nas sociedades contemporâneas, fortemente estruturadas no individualismo. George Orwell, em sua clássica obra 1984 (2003, p. 199-201), descreve com incrível precisão a intérmina luta entre as classes.

Ao longo de todo o tempo registrado e provavelmente desde o fim do Neolítico, existem três tipos de pessoas no mundo: as Altas, as Médias e as Baixas. Essas pessoas se subdividiram de várias maneiras, responderam a 
um número incontável de diferentes nomes, e seus totais relativos, bem como sua atitude umas para com as outras, têm variado de uma época para outra: mas a estrutura primordial da sociedade jamais foi alterada. Mesmo depois de tremendas comoções e mudanças aparentemente irrevogáveis, 0 mesmo modelo sempre tornou a se formar, assim como um giroscópio sempre reencontra o equilíbrio, por mais que seja empurrado nesta ou naquela direção. Os objetivos desses três grupos são inconciliáveis. O objetivo dos Altos é continuar onde estão. O objetivo dos Médios é trocar de lugar com os Altos. O objetivo dos Baixos, isso quando têm um objetivo pois uma das características marcantes dos Baixos é o fato de estarem tão oprimidos pela trabalheira que só a intervalos mantêm alguma consciência de toda e qualquer coisa externa a seu cotidiano - é abolir todas as diferenças e criar uma sociedade na qual todos os homens sejam iguais. Assim, ao longo da história, um conflito cujas características básicas permanecem inalteradas se repete uma ou outra vez. Durante longos períodos os Altos parecem ocupar o poder de forma absolutamente inabalável, porém mais cedo ou mais tarde sempre chega o dia em que eles perdem ou a confiança em si mesmos ou a capacidade de governar com eficiência - ou as duas coisas. São derrubados pelos Médios, que angariam o apoio dos Baixos fingindo lutar por liberdade e justiça. Nem bem atingem seu objetivo, os Médios empurram os Baixos de volta para sua posição subalterna, a fim de se tornarem eles próprios os Altos. Nesse momento um novo grupo de Médios se desprende de um dos dois outros grupos, ou de ambos, e o conflito recomeça. Dos três grupos, apenas os Baixos jamais conseguem, nem temporariamente, sucesso na conquista de seus objetivos. Seria exagero dizer que ao longo da história nunca houve progresso material. Mesmo hoje, num período de declínio, o ser humano médio está fisicamente em melhor condição do que há alguns séculos. Mas nenhum progresso na área da riqueza, nenhum refinamento da educação, nenhuma reforma ou revolução jamais serviram para que a igualdade entre os homens avançasse um milímetro que fosse. Do ponto de vista dos Baixos, nenhuma mudança histórica chegou a significar muito mais que uma alteração no nome de seus senhores.

Martha Nussbaum (2013, p. 91-93), alinhada à doutrina seniana, sugere uma lista com capacidades humanas centrais que envolvem os seguintes aspectos: a) vida; b) saúde física; c) integridade física; d) sentidos, imaginação e pensamento; e) emoções; f) razão prática; g) afiliação; h) outras espécies; i) lazer; j) controle sobre o próprio ambiente.

Segundo a filósofa norte-americana (2013, p. 84-91), a melhor abordagem de um mínimo social básico é fornecida por uma explicação que se concentre nas capacidades humanas, isto é, no que as pessoas são capazes de fazer instruídas pela ideia intuitiva de uma vida apropriada à dignidade humana. Por outro lado, o enfoque das capacidades não pretende fornecer uma explicação completa da justiça social. Nada diz sobre como a justiça trata desigualdades acima do nível mínimo. Essa afirmação demanda duas considerações. 
Primeira consideração. $O$ investimento no conjunto capacitário humano não fornece uma explicação completa da justiça social. Isso significa que, não obstante exista uma explicação completa de justiça social, não é esse o objetivo do enfoque das capacidades.

Para compreender a lógica dessa ressalva, recorre-se à teoria econômica do segundo melhor (second best). Em economia, se a eficiência perfeita (first best) não pode ser obtida, admite-se que o segundo melhor resultado (second best) implique a veiculação de medidas estranhas ao que, a princípio, seria considerado o cenário perfeito. Assim, se a conjuntura desfavorece escolhas voltadas à solução ideal, pode-se exigir do Estado a adoção de outras ações, mesmo que elas se afastem dos pressupostos idealizados prioritariamente.

Com ajustes, pode-se dizer que o princípio da igualdade plena seria a melhor abordagem (first best), e o princípio da diferença (que reconhece as diferenças e as utiliza em benefício dos menos favorecidos com o intuito de reduzir as desigualdades), a segunda melhor abordagem (second best).

Segunda consideração. A opção de investir em um nível mínimo de capacidades nos mais variados aspectos (saúde, razão prática etc.), apesar de não focalizar especificamente na redução das desigualdades, indiretamente contribui (e muito) para a redução das desigualdades. A ilustração a seguir explica o porquê.

$\mathbf{S}_{1}$

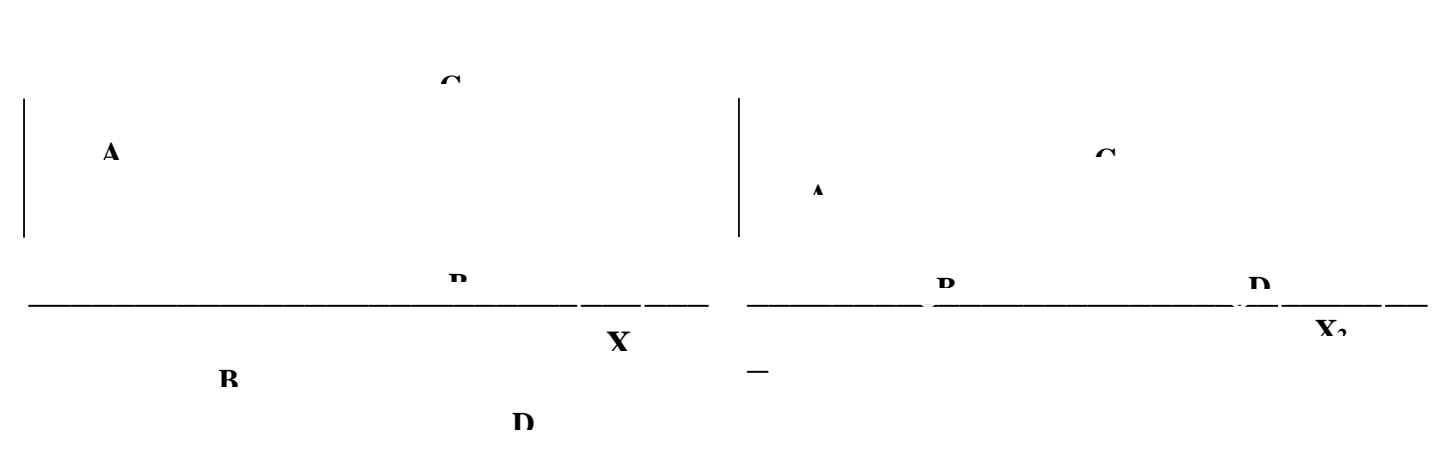

Tome-se como referências as sociedades hipotéticas $\mathrm{S}_{1}$ e $\mathrm{S}_{2}$. Considerandose que os conjuntos capacitários mínimos sejam representados pelas linhas imaginárias $X_{1}$ e $X_{2}$, percebe-se que: $\left.1^{\circ}\right)$ os cenários das duas sociedades $\left(S_{1}\right.$ e $\left.S_{2}\right)$ 
revelam desigualdades socioeconômicas entre os indivíduos $\left(S_{1}: C_{1}>A_{1}>B_{1}>D_{1}\right.$; S2: $\left.C_{2}>A_{2}>B_{2}>D_{2}\right) ; 2^{\circ}$ ) na sociedade $S_{2}$, as desigualdades são menores, porquanto os conjuntos capacitários de $\mathrm{B}_{2}$ e $\mathrm{D}_{2}$ foram elevados ao nível $\mathrm{X}_{2}$; $3^{\circ}$ ) os conjuntos capacitários de $A_{2}$ e $C_{2}$, respectivamente, são um pouco inferiores aos conjuntos capacitários de $A_{1}$ e $C_{1}$. Isso se deve ao fato de que o capital necessário para a implementação das políticas públicas emana da riqueza dos indivíduos, até porque o Estado não produz riqueza. Elevar o nível capacitário de $B_{2}$ e $D_{2}$ somente é possível graças a mecanismos compulsórios de redistribuição, normalmente materializados através de tributos.

A conclusão é que o investimento na valorização do homem, ao potencializar a habilidade do Estado de elevar os variados padrões de existência a um patamar íntegro, reduz significativamente os desníveis sociais. A estratégia de buscar diretamente a igualdade socioeconômica é perigosa, diante do risco de comprometer o pacto solidário de cooperação mútua. Assim, o combate à exclusão social não deve ser justificado com fundamento na redução das desigualdades sociais, e sim na promoção da inclusão social. Trata-se de mecanismos diferentes com resultados convergentes. Aos olhos da classe média, nas egocêntricas sociedades contemporâneas, o discurso "vamos empreender esforços para resgatar as pessoas que vivem em situação de miséria" é bem mais atraente do que "vamos dar aos pobres a mesma condição da classe média".

\section{INDIVIDUALISMO E COLETIVIDADE}

Neste trabalho, parte-se do pressuposto de que a ideologia dos iguais, além de falaciosa, compromete o futuro dos grupos. Nesse sentido, considera-se que a separação em estamentos dos mais variados tipos (profissionais e socioeconômicos, p. ex.) é um fator indispensável para que as engrenagens sociais imprimam movimentos geradores de riqueza e bem-estar. Em uma comunidade aborígene que habita espaços remotos do globo, decerto existe um propósito de cooperação social que serve como critério para a divisão das tarefas. Nesses grupos, uma criança não possui o direito de escolher seu papel na fase adulta. Qual seria o destino da 
coletividade se todas as crianças optassem pela caça de animais? Quem cultivaria o solo? Quem cuidaria dos doentes? Sob esse ponto de vista, parece razoável defender que a vontade coletiva prevalece sobre o somatório dos interesses individuais. As bases da cooperação social gravitam em torno do mutualismo.

Quanto maior a coletividade, menores são as amarras que limitam a vontade individual. Essa característica da modernidade pode conduzir à falsa ideia de que os indivíduos são livres. Na sociedade contemporânea, os enlaces sociais, apesar de remotos, vinculam e, consequentemente, limitam a liberdade de escolher. A título de ilustração, compete ao Estado autorizar a oferta de vagas para cursos universitários. Se o Estado concluir que não existe reserva de mercado para novos advogados em virtude do risco de obsolescência decorrente da automação jurídica, ele poderá suspender a criação de novos cursos de Direito. Portanto, ninguém possui o direito de ser advogado. A pessoa só possui o direito de ser advogada, se o Estado tiver interesse na graduação de novos advogados.

Essa perspectiva é primordial para desconstruir a distorcida ideia de que o Direito é uma ciência de direitos subjetivos. Sob esse viés, a noção de dever é acessória, quase um efeito colateral do direito, ou seja, uma indigesta consequência do sinalagma relacional. Evidentemente, não se nega a importância de apresentar o direito tributário como um direito do contribuinte ou o direito processual penal como um direito do réu ao devido processo legal. Aliás, é imprescindível avistar o direito como um eficiente sistema de garantias que protege o cidadão do avanço parasitário do Estado. O equívoco está em limitar a abordagem do direito ao aspecto subjetivo, quando, na realidade, existem deveres fundamentais autônomos e independentes. Todos devem ter a consciência de que o que torna possível a vida em comunidade é a consciência sobre os deveres.

Para Casalta Nabais (on line), os deveres ou custos dos direitos constituem a responsabilidade comunitária que os indivíduos assumem ao integrar uma comunidade organizada, mormente uma comunidade organizada no estado (moderno). Um desses deveres fundamentais envolve o pagamento de tributos. $\mathrm{O}$ cidadão tem o dever pagar tributos sem nenhuma expectativa de retorno concreto e individualizável. Logo, mesmo que um indivíduo de classe média seja usuário de 
serviços privados de saúde, ele possui o dever de contribuir para a saúde pública. A mesma lógica vale para todos os segmentos da ordem social.

O dever de contribuir, de certo modo, caracteriza um seguro da humanidade em face das variáveis aleatórias da vida. Até onde se sabe, ninguém possui a capacidade de planejar e projetar o seu próprio nascimento. Ninguém dispõe do direito de escolher a nacionalidade ou o coeficiente de riqueza de seus genitores. A opção por um sistema compulsório de redistribuição pode então ser associada ao véu da ignorância rawlsiano (Rawls, p. 146) e à estratégia de maximização do mínimo (maxmin). Esse é um argumento válido inclusive para os adeptos do libertarismo. Com efeito, ainda que um libertário repugne qualquer espécie de subtração patrimonial por parte do Estado, possivelmente, ele concordaria em proporcionar aos seus descendentes um mínimo essencial. Ora, se a geração atual não possui o dom de prever a situação socioeconômica de seus descendentes, não existe nada mais tranquilizador do que saber que a coletividade amparará os cidadãos em caso de vulnerabilidade.

Como então justificar a obrigação de os cidadãos produtores ajudarem os hipossuficientes? Na verdade, não há porque buscar justificativas minudentes. Em um país, o pacto de cooperação social, matriz do modelo compulsório de solidariedade, é o fundamento para a realização do compromisso constitucional de que todos os seres humanos têm 0 direito de praticar funcionamentos verdadeiramente humanos. Preceitos programáticos não são quase-direito (soft law) e nem perdem a estatura de norma constitucional em virtude do caráter abstrato de suas disposições.

\section{ESCASSEZ}

Um dos principais instrumentos jurídicos de combate à exclusão social é a assistência social. Esse subsistema de índole protetiva atua para minimizar um grave problema da humanidade: a escassez de dinheiro.

Sendhil Mullainathan e Eldar Shafir (2016, p. 14) defendem que a escassez é mais do que o simples desprazer de ter muito pouco. A escassez muda a maneira 
de pensar. Ela se impõe na mente humana, capturando a mente dos participantes, que se direciona para as necessidades não supridas. A fome nada mais é senão um caso extremo: envolve escassez, mas também envolve muitas mudanças fisiológicas.

Os autores (Mullainathan; Shafir, 2016, p. 22) associam a escassez a expressão metafórica "entrar no túnel", no sentido de que ela (a escassez) leva o ser humano a concentrar a atenção na administração da escassez imediata. Como o foco na escassez é involuntário e captura a atenção, ele impede a capacidade de focar em outras coisas.

A escassez em uma área da vida significa menos atenção, menos concentração, em síntese, menos mente nas demais áreas. A esse fenômeno, Mullainathan e Shafir referem-se como "largura de banda" (2016, p. 38). A largura de banda mede a capacidade computacional ou a capacidade de prestar atenção para tomar boas decisões, manter os planos e resistir a tentações. A largura de banda está relacionada a tudo, desde inteligência e desempenho até controle de impulsos e sucesso em dietas. Ao puxar constantemente de volta para o túnel, a escassez taxa a largura de banda e, como resultado, inibe as capacidades centrais.

Compreender a psicologia da escassez é um pressuposto fundamental para identificar a gênese da exclusão. A pobreza vai muito além da escassez de dinheiro. O pobre não tem apenas pouco dinheiro. Ele tem pouca largura de banda. Com a escassez na mente, ele dispõe de menos espaço para todas as outras coisas. Menos espaço significa menos liberdade. Em última instância, a pobreza compromete significativamente a liberdade de escolha. Em "Desenvolvimento como liberdade", Amartya Sen (2000, p. 22-23) relata uma trágica experiência sobre a escassez.

Certa tarde, estava brincando no jardim de minha casa na cidade de Dhaka (...), quando um homem entrou pelo portão gritando desesperadamente e sangrando muito. Fora esfaqueado nas cotas. Era a época em que hindus e mulçumanos matavam-se nos conflitos grupais que precederam a independência e a divisão de Índia e Paquistão. Kader Mia, o homem esfaqueado, era um trabalhador diarista mulçumano que viera fazer um serviço em uma casa vizinha - por um pagamento ínfimo - e fora esfaqueado na rua por alguns desordeiros da comunidade hindu majoritária naquela região. Enquanto eu lhe dava água e ao mesmo tempo gritava pedindo ajuda aos adultos da casa - e momentos depois meu pai o levava 


\begin{abstract}
às pressas para o hospital - , Kader Mia não parava de nos contar que sua esposa lhe dissera para não entrar em uma área hostil naquela região tão conturbada Kader Mia precisava sair em busca de trabalho e um pouco de dinheiro porque sua família não tinha o que comer. A penalidade (...) acabou sendo a morte, que ocorreu mais tarde.
\end{abstract}

Em razão da escassez econômica, Kader Mia entrou no túnel. Sua largura de banda estava comprometida com a solução da miséria. Para ele, não havia outra alternativa senão arriscar-se em território hostil em busca da sobrevivência de sua família. Paradoxalmente, sua luta por sobrevivência custou-lhe a vida.

É claro que nem todos os cenários de escassez econômica podem ser associados à pobreza. Não é incomum que famílias de elevado padrão social enfrentem momentos pontuais de escassez que levem à readequação dos gastos e, em situações mais graves, ao declínio do grupo familiar a um estamento socioeconômico inferior. Porém, sem nenhuma dúvida, a pobreza pode ser considerada um cenário de escassez econômica que transporta a pessoa para o túnel e taxa a sua largura de banda.

Há provas abundantes de que o desemprego tem efeitos abrangentes além da perda de renda, como dano psicológico, perda de motivação para o trabalho, perda de habilidade e autoconfiança, aumento de doenças e morbidez (e até mesmo taxas de mortalidade), perturbação das relações familiares e da vida social, intensificação da exclusão social e acentuação de tensões raciais e das assimetrias entre os sexos (SEN, 2000, p. 117). Se a angustiante procura por emprego formal é a causa de tantos males, o que dizer da luta pela sobrevivência?

Um levantamento divulgado na Síntese de Indicadores Sociais 2017 (on line) revelou que, no ano de 2016, 25,4\% da população brasileira vivia em situação de pobreza. Na apuração, utilizou-se o critério do Banco Mundial, que considera pobre quem ganha menos do que US\$5,5 por dia nos países em desenvolvimento.

Ainda que direitos sociais de ótima qualidade sejam colocados à disposição da população, a psicologia da escassez remove do cidadão miserável a possibilidade de satisfação de seus direitos sociais. Qual seria a prioridade de um pai de família desempregado: buscar cursos de qualificação profissional, fornecidos gratuitamente pelo Estado, os quais, sem nenhuma dúvida, Ihe possibilitariam melhores oportunidades de emprego, ou mendigar míseros reais para a 
sobrevivência da família? Mesmo para aqueles que optassem pela capacitação, será que eles teriam a atenção necessária (leia-se: largura de banda) para compreender o conteúdo ministrado? O túnel da pobreza é uma armadilha, e a pobreza é cíclica.

\section{A FOLGA}

Amartya Sen (2000, p. 18) sustenta que o crescimento do Produto Nacional Bruto (PNB) e o aumento das rendas pessoais, apesar de importantes mecanismos de expansão das liberdades, caracterizam uma visão bastante restrita de desenvolvimento. Para ele, a verdadeira (e única) acepção de desenvolvimento impõe a remoção das principais fontes de privação de liberdade: pobreza e tirania, carência de oportunidades econômicas e destituição social sistemática, negligência dos serviços públicos e intolerância ou interferência excessiva de Estados repressivos.

A análise de desenvolvimento pautada em um critério de cálculo pela "média" pode omitir informações relevantes sobre as condições de vida da população. Conforme salientado Angus Deaton (2017, p. 21), não se pode avaliar o bem-estar pela média sem levar em conta a desigualdade e a análise do todo. Se, em uma microcomunidade de dez sujeitos, um deles auferir renda mensal de duzentos mil reais, e os demais auferirem rendimentos mensais de um mil reais, o cálculo aritmético da renda per capita $(R \$ 20.900,00)$ fornecerá um dado destoante da realidade. Qualquer análise socioeconômica minimamente alinhada à realidade deve ser pautada em números absolutos e em informação descritiva.

Segundo dados do Fundo Monetário Internacional de 2015 (Estadão, on line), o PIB per capita no Brasil foi de US\$15 mil. Já com base no modelo descritivo de avaliação, sabe-se que 52 milhões de brasileiros vivem em situação de pobreza. Está-se diante de duas informações verdadeiras que sugerem quadros sociais mui diferentes. Optar pelo estudo descritivo é o marco zero da tomada de uma decisão política.

Para Mullainathan e Shafir, não se tira férias da pobreza (2016, p. 178). Trata-se de uma meia verdade. Sempre existe a possibilidade de transposição 
individual da linha da pobreza. Sempre existe a possibilidade de um pobre escapar do túnel. Às vezes, a transposição decorre de eventos fortuitos, como prêmios e sorteios. Outras vezes, a mobilidade social é consequência exclusiva do extraordinário mérito de indivíduos super-humanos que superam a pouca largura de banda e se tornam role models².

Mas nenhuma regra se constrói a partir de exceções. Considerando que o cenário social de miséria é intolerável, e que episódios isolados de mobilidade social não resolverão os graves problemas sociais no Brasil, só resta uma alternativa: alguém (quem?) precisa fazer alguma coisa (o quê?) para retirar o grande público de miseráveis (de dentro) do túnel.

(Quem?) Obviamente, no âmbito de um território soberano, esse alguém é o Estado. Auxílios provenientes de entidades não governamentais caracterizam filantropia, a mais nítida manifestação (impessoal) de solidariedade.

(O quê?) O Estado precisa guiar, e não apenas orientar, a população em direção à saída do túnel. Novamente, não adianta fornecer educação de qualidade a uma pessoa que não possui largura de banda porque foi capturada pela armadilha da escassez. Um eficiente programa público de combate à pobreza recomenda ajustes ao milenar provérbio chinês "dê um peixe a um homem faminto e você o alimentará por um dia; ensine-o a pescar, e ele se alimentará pelo resto da vida".

A questão social costuma ser apresentada como se as duas providências (give a fish e teach how to fish) fossem excludentes, o que não é verdade. $\mathrm{Na}$ realidade, não existe uma oposição entre "dar o peixe" e "ensinar a pescar". Por que não fazer os dois? Escolher um dos caminhos, excluindo o outro, perpetua o ciclo da pobreza.

A opção exclusiva de "dar o peixe" suplanta a concepção razoável de paternalismo, pois promove a dependência e a dominação, autênticos mecanismos antidemocráticos. De outro lado, a opção exclusiva de "ensinar a pescar" é equívoca, seja em virtude da pouca largura de banda da população, seja em razão dos dois principais entraves mercadológicos do século XXI: o grau de instrução (quem contrataria um analfabeto?) e a experiência profissional (quem contrataria

2 Personalidades simbólicas oriundas de grupos sociais discriminados que conquistaram sucesso pessoal e profissional e que, por isso, funcionam como modelo para gerações mais jovens. 
uma pessoa sem experiência profissional?). Ora, em tempos hipermodernos de indústria 4.0, de dinamismo extremo e exigência de resultado imediato, será que um pai de família analfabeto estaria disposto a abrir mão da mendicância, que the garante resultado imediato (alguns míseros reais) em troca do conhecimento (ler e escrever)?

Defender que a grande saída para o problema da pobreza depende de melhorias na saúde e na educação está longe de ser um argumento inédito. Praticamente existe uma unanimidade quanto a essa orientação. $O$ que se defende é que sempre existe um primeiro passo para a solução de quaisquer problemas ou fissuras de natureza social. Esse primeiro passo é a "folga".

Mullainathan e Shafir (2016, p. 134) sustentam que a "folga" está no cerne da psicologia da escassez. Para eles, a folga é um luxo mental, que possibilita o sentimento de abundância. Obviamente, há necessidade de adequar a ideia de folga construída pelos autores ao contexto da pobreza. Nesse sentido, defende-se que a folga signifique suficiência, e não abundância. A folga permite a segurança pressuposta de que as necessidades elementares serão supridas. Significa dispor de um numerário suficiente para não ser capturado pela escassez. Sem fome, o indivíduo estaria apto a aprender a pescar. Garantida a subsistência da família, o cidadão estaria livre para se capacitar em busca de melhores oportunidades. Essa folga, de natureza pecuniária, é materializada por meio de programas assistenciais de transferência de renda.

Portanto, se alguém tivesse que eleger a providência preliminar para melhoria das condições sociais, a melhor escolha não seria educação, saúde ou trabalho. Seria a folga, entendida como suficiência pressuposta, isto é, uma renda mínima capaz de resolver o gravíssimo problema da escassez econômica.

\section{A RENDA}

Modelar o programa de transferência de renda é uma tarefa árdua. Muitas variáveis relevantes precisam ser levadas em consideração. Três delas merecem um 
exame mais cuidadoso: $1^{\mathrm{a}}$ ) a titularidade; $2^{\mathrm{a}}$ ) $\mathrm{O}$ valor do benefício; $3^{\mathrm{a}}$ ) a periodicidade da transferência.

Titularidade. O filósofo e economista político belga Philippe Van Parijs (2014) defende a instituição de um programa universal de transferência de renda. Em seu artigo "Por que os surfistas devem ser alimentados: o argumento liberal em defesa de uma renda básica incondicional", Van Parijs conclui que os surfistas de Malibu têm direito a uma renda individual que independe de quaisquer condicionalidades, como a situação financeira e o trabalho.

Anthony Atkinson (2015, p. 267-268) propõe uma variação sutilmente diferente da renda básica universal: a instituição de um benefício que não seja pago em razão da cidadania, mas na participação do indivíduo. Haveria, pois, uma única condição de elegibilidade para o amparo: a participação, definida genericamente como uma contribuição social (emprego assalariado, trabalho voluntário etc.).

De fato, a renda básica universal e incondicional não pode ser considerada uma alternativa interessante em um mundo globalizado de frágeis fronteiras assimétricas. A principal vantagem de optar pelo critério da participação é o fortalecimento da solidariedade e de sua mensagem positiva sobre reciprocidade. Porém, a participação é um critério da elegibilidade subjetivo, característica que pode levar a embaraços interpretativos na administração do programa. Considerando que o Estado gere o dinheiro público com ineficiência, sempre é recomendável a previsão de critérios objetivos.

Portanto, a melhor estratégia é condicionar a transferência de renda a três critérios puramente objetivos: a nacionalidade brasileira, a identificação pelo cadastro nacional (no Brasil, o Cadastro de Pessoas Físicas - CPF) e a residência em território nacional. Apenas excepcionalmente, na hipótese de reciprocidade entre Estados, seria legítima a concessão do amparo assistencial a estrangeiros.

Observados então os dois únicos critérios de elegibilidade (identificação cadastral e territorialidade), o benefício de renda básica seria devido independentemente das circunstâncias socioeconômicas do beneficiário (classe social, renda per capita, estar em atividade etc.) e de quaisquer outras condicionalidades (vacinação e matrícula obrigatória dos filhos). Seguramente, tratase de uma proposta valiosíssima que mereceria maior atenção dos governantes. 
Curiosamente, no Brasil, existe base legal para um programa social de abrangência universal. Em janeiro de 2004, a Lei 10.835 instituiu a renda básica de cidadania, prestação pecuniária acessível a todos os brasileiros residentes no País e estrangeiros residentes há pelo menos cinco anos no Brasil, independentemente de sua condição socioeconômica, com a observância das seguintes diretrizes: $1^{\text {a }}$ ) universalização gradual da prestação a critério do Poder Executivo, com a indicação expressa de priorização das camadas sociais mais vulneráveis; $2^{a}$ ) 0 amparo não seria objeto de tributação; $3^{a}$ ) o valor do benefício, que seria igual para todos, deveria ser suficiente para atender às despesas mínimas de cada pessoa com alimentação, educação e saúde, devendo-se considerar o grau de desenvolvimento do País e as possibilidades orçamentárias; $4^{a}$ ) a definição do valor seria competência do Poder Executivo, em estrita observância ao disposto nos arts. 16 e 17 da Lei de Responsabilidade Fiscal.

Passados quatorze anos, a renda básica de cidadania ainda não foi

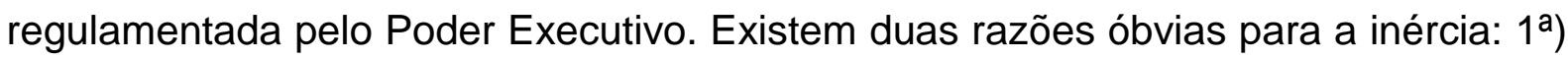
um benefício condicionado à disponibilidade orçamentária não pode ser considerado propriamente um direito por inexistência de exigibilidade jurídica; $2^{\mathrm{a}}$ ) a previsão legal da Renda Cidadania é contemporânea à instituição do Bolsa Família. Essa coincidência, por óbvio, contribuiu para o seu esquecimento.

O discurso sobre a renda básica (quase) incondicional, inevitavelmente, atrai respeitáveis contra-argumentos. Os dois mais importantes são o risco de a renda assistencial estimular o ócio dos beneficiários com impactos na economia e o custo orçamentário do programa.

Em relação à primeira crítica, de fato, trata-se de uma preocupação legítima. O valor da transferência é um dos eixos centrais do programa. Ele não pode ser insignificante (que torne inviável o combate à miséria) nem alto demais (a ponto de estimular a ociosidade). O amparo, entenda-se a folga, deve ser suficiente para resgatar as pessoas da situação de miséria (suficiência pressuposta).

Com isso, quer-se dizer, mais uma vez, que a renda transferida não pode proporcionar a sensação de abundância. A prudência não está apenas na definição de seu valor. Outro aspecto fundamental diz respeito à periodicidade das transferências. Mullainathan e Shafir (2016, p. 230-231) lembram que, 
eventualmente, a escassez começa com a abundância. Segundo sustentam, uma maneira de combater o ciclo de abundância seguida de escassez é equilibrá-lo, criando longos períodos de moderação, em vez de surtos de abundância seguidos de intensos períodos de escassez. Uma pessoa pobre que recebe uma única quantia (considerável para os seus padrões) no início de um mês entra em um ciclo semelhante de abundância seguido de escassez. Logo, dividir o pagamento em partes gradativas pode ajudar a controlar a psicologia da abundância. E se o beneficiário não recebesse todo o dinheiro de uma só vez no início do mês, mas com uma regularidade maior? Por que não pagar os benefícios semanalmente? Ou, se necessário, fazer uma combinação: um pagamento inicial grande para cuidar das grandes despesas mensais e depois pagamentos menores para as despesas semanais?

A opção de quase universalizar o auxílio financeiro, ao invés de focalizá-lo à população hipossuficiente, dispensa o teste de meios (teste de pobreza) e previne possíveis distorções resultantes de tentativas de direcionamento ambíguo das políticas (SEN, 2000, p. 161). Identificam-se três aspectos principais.

Primeiro. Vincular a cessação de um benefício assistencial à superação de determinado patamar de renda não pode ser considerado um bom mecanismo de seletividade, pois impulsiona a desocupação e o trabalho informal, considerando o risco de obliteração do amparo público em virtude da percepção de renda formal (Leitão; Dias; Freitas, 2017). Amartya Sen (2000, p. 161) refere-se a isso como distorção do incentivo. Os custos sociais da mudança de comportamento econômico precisam incluir, entre outras coisas, a perda dos frutos das atividades econômicas das quais se abriu mão.

Segundo. O teste de pobreza, em si, demanda um enorme gasto para o Estado, que precisa dispender quantias significativas com pessoal (servidores públicos) e sistemas de informação para controle de fraudes. A título de ilustração, uma auditoria da Controladoria-Geral da União (CGU) no Bolsa Família identificou 345.906 cadastros com indícios de fraude. São casos de beneficiários que não teriam direito ao programa por estarem fora das regras estabelecidas, em especial por terem seus rendimentos mensais acima do patamar de $\mathrm{R} \$ 170$ (O Globo, on line). 
Terceiro. Um sistema de custeio público que exija a identificação da pessoa como pobre contribui para a estigmatização da pobreza e produz alguns efeitos sobre o respeito próprio e sobre o respeito dos outros pela pessoa (Sen, 2000, p. 162). Deveras, a complexidade inerente à burocracia dos formulários cria problemas de adesão, sobretudo para pessoas com pouca instrução. O resultado prático é que nem todos os que têm direito ao benefício acabam por solicitá-lo (Atkinson, 2015, p. 256-257).

A segunda preocupação, que envolve o custo orçamentário do programa, também é importante. Em The cost of rights - why liberty dependes on taxes, Cass Sunstein e Stephen Holmes (1999) concluem que todos os direitos são positivos e decorrem da disponibilização de remédios jurídicos para a respectiva proteção em face de eventuais violações (omissivas ou comissivas). Titularizar um direito significa ostentar sempre a condição de potencial autor de um processo judicial. Os remédios jurisdicionais demandam a criação e a manutenção de uma complexa estrutura pública de modo a assegurar o acesso a uma esfera própria para a tutela dos direitos.

A consciência de que direitos não nascem em árvores (Galdino, 2005, p. 346) solapa o mito do governo grátis (Castro, 2014). Não existem prestações públicas gratuitas. Por essa razão, não se cria despesa sem a expectativa de um eficiente retorno social, afinal o orçamento público não é uma fonte inesgotável de recursos.

A experiência assistencial no Brasil é protagonizada pelo Bolsa Família, instituído pela Medida Provisória №. 132, de 20 de outubro de 2003, posteriormente convertida na Lei o․ 10.836, de 9 de janeiro de 2004. O escopo do programa foi a unificação dos procedimentos de gestão e execução de ações de transferência de renda do Governo Federal por meio de um único registro (Cadastro Único para Programas Sociais do Governo Federal). Com isso, valores antes recebidos separadamente passaram a ser pagos em parcela única (Leitão; Dias; Freitas, 2017).

Para 0 ano de 2018, estima-se a despesa de 28,7 bilhões de reais com 0 Bolsa Família (Gazetaweb, on line). Esse montante beneficiará 45,8 milhões de pessoas. Isso significa que um em cada quatro brasileiros está no Bolsa Família 
(Gazetaweb, on line). Não obstante a despesa seja expressiva em números absolutos, o mesmo não se pode dizer em termos relativos. Segundo estudo realizado pelo IPEA em 2013, no ano de 2009, o Bolsa Família custava aproximadamente $0,4 \%$ do PIB (Campello; Neri, 2013, on line). Apenas para se ter ideia do ínfimo custo relativo do programa, segundo dados do portal da transparência do governo federal (Brasil, on line), em 2017, a despesa da União com servidores superou 200 bilhões de reais. Por consectário, definitivamente, o Bolsa Família não custa caro para a sociedade brasileira.

E se o Bolsa Família fosse realmente substituído pela renda básica (quase) universal (em moldes semelhantes à renda básica de cidadania, prevista na Lei 10.835/04)? Quais seriam os impactos econômicos e sociais?

Seguramente, haveria o crescimento da despesa imediata, afinal o número de beneficiários aumentaria significativamente. Porém, uma estratégia que reduziria o custo do programa seria a transformação da natureza jurídica do amparo, que deixaria de ser indenizatório e passaria a ser remuneratório. Com isso, observado o limite de isenção, os valores percebidos seriam objeto de tributação sobre a renda. O ajuste anual de incidência seria realizado por ocasião da declaração do imposto de renda ${ }^{3}$.

Sob outra perspectiva, a quase universalização do programa dispensaria a manutenção da atual estrutura administrativa de controle. Condicionar o benefício à nacionalidade brasileira, à apresentação do CPF e à prova de residência despenderia menos dinheiro e esforço de fiscalização do que a análise sobre a renda, sendo certo que menos esforço de fiscalização significa menos dinheiro.

Além do mais, de acordo com o IPEA (Campello; Neri, 2013, on line), o Bolsa Família é, por larga margem, a transferência com maiores efeitos. O IPEA constatou um aumento de $R \$ 1,78$ no PIB para um choque marginal de $R \$ 1,00$ no benefício. Ou seja, se a oferta fosse perfeitamente elástica, e os demais pressupostos fossem respeitados, um gasto adicional de $1 \%$ do PIB no Bolsa Família implicaria em um aumento de $1,78 \%$ na atividade econômica. Quanto mais

\footnotetext{
3 A sistemática de tributação deste benefício seria um dos aspectos centrais do programa. A incidência do imposto seria, indiretamente, um importante critério de seletividade para o benefício. Este ensaio não se propõe a apresentar uma proposta minuciosa do ponto de vista tributário. Porém, defende-se a tributação progressiva com alíquotas marginais superiores às atuais.
} 
focalizadas forem as transferências para os pobres, maiores serão seus respectivos efeitos multiplicadores. Isso acontece porque a população hipossuficiente, em virtude da escassez, possui maior propensão marginal para o consumo, na medida em que todas as suas receitas tendem a estar previamente comprometidas com alguma despesa predefinida. Essa não é a realidade dos estamentos sociais mais elevados, que acumulam riqueza em poupança. Essa reserva financeira sai do fluxo circular da renda e não tem efeitos multiplicadores sobre a atividade econômica (Campello; Neri, 2013, on line).

Também não se pode desconsiderar a nítida relação entre a renda básica e o mundo laboral sob a ótica do trabalho decente. Com efeito, graças a segurança financeira proporcionada pela transferência mensal, muitos miseráveis passariam a ter o direito de escolher exercer um trabalho decente. A propósito, escolher, por si só, pode ser considerado um funcionamento bastante valioso. Some-se a isso o ganho em produtividade decorrente do crescimento potencial da qualidade do trabalho desenvolvido pelo beneficiário do programa, o qual já não mais estaria confinado no túnel da escassez. Menos escassez, maior largura de banda, melhor produtividade.

Não se pode olvidar ainda que a instituição de uma renda básica (quase) universal e incondicional, possivelmente, fomentaria a inclusão previdenciária. Se a formalização do trabalho não ameaçasse o cancelamento da prestação assistencial, haveria boa chance de as pessoas saírem da informalidade e contribuírem para a previdência social.

Não apenas isso. Uma renda melhor, a priori, significaria uma alimentação mais equilibrada e rica em nutrientes essenciais para uma vida saudável. Se o Estado erradicasse a fome, combatesse a desnutrição e elevasse a qualidade da alimentação, certamente, economizaria com a saúde pública.

O último argumento em favor da renda básica remete à situação hipotética apresentada no início deste ensaio. Quem daria uma esmola para um homem, aparentemente hígido, de meia idade e de pouca instrução? Talvez algumas pessoas, sensibilizando-se com a situação de miserabilidade, dessem alguns trocados. Porém, sem nenhuma pesquisa sociológica prévia, supõe-se que a maioria 
da população com capacidade econômica negaria o auxílio sob o argumento de que aquele pedinte teria plena condição de trabalho. A questão é "quem o contrataria?"

Como salientado por Robert Castel (Wanderley; Bógus; Yazbek, 2017, p. 3941), normalmente, o pensamento e a luta contra a exclusão correspondem a um tipo clássico de focalização da ação social: delimitar zonas de intervenção que podem dar lugar às atividades de reparação. A tradição da ajuda social define "populaçõesalvo" a partir de um déficit preciso. Cristalizaram-se categorias cada vez mais numerosas de populações advindas de um regime especial: inválidos, pessoas com deficiência, idosos economicamente vulneráveis, crianças em dificuldade, famílias monoparentais etc. Para o sociólogo francês, as políticas públicas em geral optam pela categorização e isolamento de grupos com problemas. Criam-se meios de uma tomada de responsabilidade específica e cuidadosamente focada, ao invés de implementar ações mais ambiciosas (e obviamente mais custosas).

O ponto é que a sociedade não pode simplesmente ignorar as novas populações que sofrem com um déficit de integração. Existe um gigantesco grupo residual de pessoas que se tornaram inválidas pela conjuntura. A própria conjuntura socioeconômica as marginalizou. Jacques Donzelot refere-se a essas pessoas como "normais inúteis". Robert Castel prefere qualificá-las como "sobrantes" (Wanderley; Bógus; Yazbek, 2017, p. 39-41).

Considerando que a renda básica de cidadania não foi implementada, podese dizer que o ordenamento jurídico pátrio não foi municiado com nenhuma política pública de integração dos sobrantes. Imagine-se um indivíduo solitário com renda pouco superior ao limite per capita previsto para o Bolsa Família. Ele não teria direito a nenhum auxílio estatal, apesar de sua indiscutível vulnerabilidade socioeconômica.

Para Robert Castel (Wanderley; Bógus; Yazbek, 2017, p. 39-41), no coração da condição salarial, aparecem as fissuras responsáveis pela exclusão. De fato, o trabalho dignifica. Porém, o acesso ao trabalho depende de uma rede políticas públicas de emancipação que garanta aos sobrantes a autonomia individual e a liberdade de funcionamento. Evidentemente, o objetivo magno não pode ser implantado de golpe, pois toda caminhada começa com um primeiro passo. $\mathrm{O}$ primeiro passo é a renda básica. 


\section{CONCLUSÃO}

O pacto de cooperação social, matriz do modelo compulsório de solidariedade, é o fundamento para a realização do compromisso constitucional de que todos os seres humanos têm 0 direito de praticar funcionamentos verdadeiramente humanos.

É absolutamente inadmissível que um quarto da população brasileira viva em situação de pobreza. Nenhuma política pública, por mais eficiente que seja, dispõe de capacidade para isoladamente resgatar essas pessoas do túnel da escassez. Não se trata, pois, de investir apenas em educação ou em saúde. Ninguém consegue livrar-se da armadilha da escassez sem uma renda mínima suficiente para a subsistência digna.

Sabe-se que o investimento público em transferência de renda não é uma unanimidade social. Suas principais críticas envolvem basicamente o custo orçamentário e o estímulo à ociosidade. Ao longo deste ensaio, descontruíram-se os dois argumentos.

Conquanto o custo absoluto de um programa assistencial de abrangência quase universal seja expressivo, o mesmo não se pode dizer em termos relativos. Comparado a outras despesas públicas da União, o custo orçamentário da renda básica seria reduzido, sobretudo se forem levados em consideração alguns efeitos de contenção, a exemplo da incidência tributária, do forte estímulo à formalização do trabalho, da inexigibilidade de uma rigorosa gestão administrativa e, finalmente, da economia com saúde curadora resultante de uma alimentação adequada, graças à ingestão de nutrientes fundamentais.

Em relação à suposta ociosidade decorrente da percepção de uma renda mensal, defende-se o contrário. A pobreza, por si só, é um poderoso limitador de produtividade, pois coloca o indivíduo no túnel da escassez, taxando-Ihe a largura de banda para realizar atividades que não envolvam a luta pela sobrevivência (psicologia da escassez). Por óbvio, a definição do valor do auxílio é um dos aspectos condicionantes do êxito do programa. Ele não pode ser insignificante nem alto demais. $O$ amparo, entenda-se a folga, deve ser suficiente para resgatar as pessoas em situação de miséria (suficiência pressuposta). Debater políticas públicas 
de inclusão voltadas à preservação da cidadania é um desafio de enorme complexidade e de permanente evolução. Ao longo deste ensaio, defendeu-se que a instituição efetiva de uma renda básica (quase) universal, certamente, seria um primeiro grande passo.

\section{REFERÊNCIAS}

ATKINSON, Anthony. Desigualdade. O que pode ser feito? São Paulo: Leya, 2015. BRASIL. Portal da transparência. Disponível em: <http://www.portaltransparencia.gov.br> Acesso em 10 abr. 2018.

CAMPELLO, Tereza; NERI, Marcelo Côrtes (orgs.). Programa Bolsa Família: uma década de inclusão e cidadania. Brasília: Ipea, 2013. Disponível em: $<$ http://www.ipea.gov.br/portal/images/stories/PDFs/livros/livros/livro_bolsafamilia_10 anos.pdf> Acesso em 10 abr. 2018.

CASTEL, Robert. As armadilhas da exclusão. In: WANDERLEY, Mariangela Belfiore; BÓGUS, Lúcia; YAZBEK, Maria Carmelita. Desigualdade e a questão social. São Paulo: EDUC, 2017.

CASTRO, Paulo Rabello de. 0 mito do governo grátis. Rio de Janeiro: Edições de Janeiro, 2014.

DEATON, Angus. A grande saída: saúde, riqueza e as origens da desigualdade. Rio de Janeiro: Intrínseca, 2017.

ESTADÃO. Um em cada quatro brasileiros está no Bolsa-Família. Disponível em: $<$ http://politica.estadao.com.br/noticias/geral,um-em-cada-quatro-brasileiros-esta-nobolsa-familia,38787>. Acesso em 10 abr. 2018.

PIB per capita retrocede cinco anos. Disponível em: <http://economia.estadao.com.br/noticias/geral,pib-per-capita-retrocede-cincoanos, 10000056666>. Acesso em 23 abr. 2018.

GALDINO, Flávio. Introdução à Teoria dos Custos dos Direitos. Direitos não nascem em árvores. Rio de Janeiro: Lumen Juris, 2005.

GAZETAWEB. Bolsa Família deve ter corte de $\mathbf{R} \$ \mathbf{1 , 7}$ bilhão em 2018; veja áreas atingidas. <http://gazetaweb.globo.com/portal/noticia/2017/11/_43315.php>. Acesso em 10 abr. 2018. 
IBGE. Síntese de Indicadores Sociais -SIS. Disponível em: $<$ https://www.ibge.gov.br/estatisticas-novoportal/sociais/trabalho/9221-sintese-deindicadores-sociais.html?=\&t=noticias-e-releases $>$. Acesso em 28 mar. 2018.

LEITÃO, Andre Studart; DIAS, Eduardo Rocha; FREITAS, Brenda Barros. Inclusão excludente, assistência, educação e paternalismo. Revista de Direito Brasileira, v. 17, p. 306-327, 2017.

MULLAINATHAN, Sendhil; SHAFIR, Eldar. Escassez: uma nova forma de pensar a falta de recursos na vida das pessoas. Rio de Janeiro: Best Business, 2016, p. 14.

NABAIS, Casalta. A face oculta dos direitos fundamentais: os deveres e os custos dos direitos. Disponível em: <http://www.egov.ufsc.br/portal/sites/default/files/anexos/15184-15185-1-PB.pdf>. Acesso em 25 mar. 2018.

NUSSBAUM, Martha. Fronteiras da justiça. São Paulo: Editora Martins Fontes, 2013.

O GLOBO. CGU identifica $\mathbf{3 4 6}$ mil cadastros do Bolsa Família com indícios de fraude. Disponível em: <https://oglobo.globo.com/brasil/cgu-identifica-346-milcadastros-do-bolsa-familia-com-indicios-de-fraude-22252968\#ixzz5BQLhqdDV>.

Acesso em 10 abr. 2018.

ORWELL, George. 1984. São Paulo: Cia das Letras, 2003.

RAWLS, John. Uma teoria da justiça. São Paulo: Martins Fontes, 1997.

ROSANVALLON, Pierre. A crise do Estado-providência. Goiânia: Editora UNB, 1997.

SEN, Amartya. Desenvolvimento como liberdade. São Paulo: Companhia das Letras, 2000.

SOUZA, Jessé. A tolice da inteligência brasileira. São Paulo: Leya, 2015.

SUNSTEIN, Cass e HOLMES, Stephen. The cost of rights - why liberty dependes on taxes. New York: W.W. Norton and Company, 1999.

; VERMEULE, Adrian. Interpretation and institutions. Disponível em: https://pdfs.semanticscholar.org/79c1/29730f42d8e313778f65c170f7c3bf80d487.pdf. Acesso em 10 abr. 2018.

VAN PARIJS, Philippe. Por que os surfistas devem ser alimentados: o argumento liberal em defesa de uma renda básica incondicional. Revista Brasileira de Ciência Política, nำ15. Brasília, setembro - dezembro de 2014, pp. 229-264. Disponível em: <http://dx.doi.org/10.1590/0103-335220141508>. Acesso em 29 mar. 2018. 


\section{VONNEGUT, Kurt. Harrison Bergeron. Disponível em: <https://archive.org/stream/HarrisonBergeron/Harrison\%20Bergeron_djvu.txt> Acesso em 25 mar. 2018.}

